\title{
Article \\ Premade Nanoparticle Films for the Synthesis of Vertically Aligned Carbon Nanotubes
}

\author{
Abdul Hoque ${ }^{1}\left(\mathbb{B}\right.$, Ahamed Ullah $^{2}\left(\mathbb{D}\right.$, Beth S. Guiton $^{2}$ and Noe T. Alvarez ${ }^{1, *(\mathbb{C}}$ \\ 1 Department of Chemistry, University of Cincinnati, Cincinnati, OH 45221, USA; hoqueml@mail.uc.edu \\ 2 Department of Chemistry, University of Kentucky, Lexington, KY 40506, USA; ahamed.ullah@uky.edu (A.U.); \\ beth.guiton@uky.edu (B.S.G.) \\ * Correspondence: noe.alvarez@uc.edu
}

Citation: Hoque, A.; Ullah, A.; Guiton, B.S.; Alvarez, N.T. Premade Nanoparticle Films for the Synthesis of Vertically Aligned Carbon

Nanotubes. C 2021, 7, 79. https:// doi.org/10.3390/c7040079

Academic Editor: Gil Goncalves

Received: 11 October 2021

Accepted: 16 November 2021

Published: 19 November 2021

Publisher's Note: MDPI stays neutral with regard to jurisdictional claims in published maps and institutional affiliations.

Copyright: (c) 2021 by the authors. Licensee MDPI, Basel, Switzerland. This article is an open access article distributed under the terms and conditions of the Creative Commons Attribution (CC BY) license (https:// creativecommons.org/licenses/by/ $4.0 /)$.

\begin{abstract}
Carbon nanotubes (CNTs) offer unique properties that have the potential to address multiple issues in industry and material sciences. Although many synthesis methods have been developed, it remains difficult to control CNT characteristics. Here, with the goal of achieving such control, we report a bottom-up process for CNT synthesis in which monolayers of premade aluminum oxide $\left(\mathrm{Al}_{2} \mathrm{O}_{3}\right)$ and iron oxide $\left(\mathrm{Fe}_{3} \mathrm{O}_{4}\right)$ nanoparticles were anchored on a flat silicon oxide $\left(\mathrm{SiO}_{2}\right)$ substrate. The nanoparticle dispersion and monolayer assembly of the oleic-acid-stabilized $\mathrm{Al}_{2} \mathrm{O}_{3}$ nanoparticles were achieved using 11-phosphonoundecanoic acid as a bifunctional linker, with the phosphonate group binding to the $\mathrm{SiO}_{2}$ substrate and the terminal carboxylate group binding to the nanoparticles. Subsequently, an $\mathrm{Fe}_{3} \mathrm{O}_{4}$ monolayer was formed over the $\mathrm{Al}_{2} \mathrm{O}_{3}$ layer using the same approach. The assembled $\mathrm{Al}_{2} \mathrm{O}_{3}$ and $\mathrm{Fe}_{3} \mathrm{O}_{4}$ nanoparticle monolayers acted as a catalyst support and catalyst, respectively, for the growth of vertically aligned CNTs. The CNTs were successfully synthesized using a conventional atmospheric pressure-chemical vapor deposition method with acetylene as the carbon precursor. Thus, these nanoparticle films provide a facile and inexpensive approach for producing homogenous CNTs.
\end{abstract}

Keywords: vertically aligned carbon nanotubes; catalyst; catalyst support; nanoparticles; monolayer

\section{Introduction}

The synthesis of vertically aligned carbon nanotubes (VA-CNTs) on a planar substrate has been established as a method for growing high-quality CNTs with controlled lengths $[1,2]$. Conventional CNT synthesis by chemical vapor deposition (CVD) requires a catalyst-support film of aluminum oxide $\left(\mathrm{Al}_{2} \mathrm{O}_{3}\right)$ and an active metal catalyst. Furthermore, the interactions between the catalyst and catalyst support are crucial for enhancing the catalyst lifetime and VA-CNT growth [3-5]. Such catalysts are commonly prepared using traditional top-down methods, with films being deposited using physical processes such as e-beam deposition, sputtering, or atomic layer deposition. Unfortunately, these catalysts provide little control over the type of CNTs that are produced, or their diameters, which is largely due to the catalyst and catalyst support preparation method. Typically, a thin film of $\mathrm{Al}_{2} \mathrm{O}_{3}(\sim 10 \mathrm{~nm})$ is deposited as a catalyst support followed by the deposition of a thin catalyst film $(0.5-3 \mathrm{~nm}$ of $\mathrm{Fe})[6,7]$. Upon exposure to a high temperature and reduction, the catalyst layer forms densely packed islands, which act as nucleation sites for CNT growth [8]. As a result, it is nearly impossible to control the catalyst nanoparticle size, and consequently, to calculate the CNT diameter ahead of time, as the nanoparticle size generally determines the nanotube diameter [9-11]. In addition, these techniques typically require expensive instrumentation, which may have a significant impact on the large-scale production of CNTs.

The development of less expensive and well-controlled methods for depositing catalysts and catalyst supports has generated considerable research interest. Although controlling the catalyst nanoparticle size is expected to provide control over the CNT diameter, 
the preparation of monodisperse catalyst nanoparticles and their assembly into thin films is challenging, and few methods have been reported [12]. Premade catalyst nanoparticles with controlled densities and sizes can affect the number of nucleation sites and the CNT diameters, respectively [13]. Efforts in this field have demonstrated the effective growth of VA-CNT arrays [14,15], but a greater control over particle size and the build-up of catalyst monolayer films is required. Investigations of individual catalyst nanoparticles can be used to elucidate their characteristics and their catalytic activity toward CNT growth. The lower temperatures that are required for nanoparticle synthesis should favor diameter control. Moreover, wet chemistry methods for catalyst and catalyst support deposition for CNT synthesis should be less expensive than traditional physical evaporation methods.

The deposition of catalyst nanoparticles on a substrate by drop casting has a limited ability to provide uniform monolayer films [16]. In contrast, the assembly of a uniform nanoparticle monolayer on a chemically functionalized substrate is a suitable technique $[14,17,18]$. An $\mathrm{Al}_{2} \mathrm{O}_{3}$ catalyst support layer consisting of premade nanoparticles can prevent catalyst diffusion [19] and increase hydrocarbon decomposition [20]. However, there are many challenges associated with assembling nanoparticles in solution into a continuous thin film, including particle diameter uniformity (monodispersion) and the packing of nanoparticles into high-density two-dimensional films while avoiding the formation of double or multiple layers. The assembly of nanoparticle monolayers on planar substrates has been explored using crosslinking agents as anchoring groups [21-24]. (3-Aminopropyl)triethoxysilane has been applied as an intermediate ligand for the formation of monolayers of nanoparticles with amino $\left(-\mathrm{NH}_{2}\right)$ groups, which can bind with or replace other organic functional groups $[25,26]$. Monolayers of iron oxide $\left(\mathrm{Fe}_{3} \mathrm{O}_{4}\right)$ nanoparticles on glass plates were successfully assembled using a hydroxypropyl cellulose (HPC) biopolymer thin film, with the HPC intermediate linkers forming hydrogen bonds with both the substrate and nanoparticle surfaces [27]. Therefore, it is understood that nanoparticle assembly as a monolayer depends on the organic or inorganic coating on the nanoparticle surface and the chemical nature of the substrate.

Oleic acid is a carboxylate-containing long-chain organic molecule that is used as a surface stabilizing agent for nanoparticle synthesis [28]. $\mathrm{Al}_{2} \mathrm{O}_{3}$ or $\mathrm{Fe}_{3} \mathrm{O}_{4}$ nanoparticles coated with oleic acid can be assembled into a monolayer on a substrate by using organic linker molecules. Bifunctional 11-phosphonoundecanoic acid (PNDA) is a suitable linker that can bind to a metal oxide substrate via its phosphonate group to form a carboxylic acid thin film [21,29]. The carboxylate groups in both oleic acid (on the nanoparticle surfaces) and PNDA (on the metal oxide substrate) can undergo ligand exchange reactions in solution. Chemically bonded carboxylate groups on $\mathrm{Fe}_{3} \mathrm{O}_{4}$ nanoparticles can facilitate the formation of a uniform monolayer of catalyst particles on a substrate. Monolayer formation on a substrate that is modified with an organic ligand can increase both the uniformity and particle density on the substrate. These features are advantageous, as it has been reported that a high density of catalyst particles is required to grow VA-CNTs $[30,31]$.

Here, we report the bottom-up assembly of premade nanoparticle monolayer films of $\mathrm{Al}_{2} \mathrm{O}_{3}$ and $\mathrm{Fe}_{3} \mathrm{O}_{4}$ for the synthesis of VA-CNTs. Using spherical nanoparticles that were synthesized in solution, $\mathrm{Al}_{2} \mathrm{O}_{3}$ and $\mathrm{Fe}_{3} \mathrm{O}_{4}$ monolayers were sequentially assembled on an $\mathrm{SiO}_{2}$ substrate. Nanoparticle separation was performed in order to enhance the homogeneity of the assembled monolayer films. The obtained nanoparticle films were then successfully applied to catalyze the growth of VA-CNTs.

\section{Experimental}

Materials: Aluminum chloride (Reagents Plus, $\geq 99 \%$ ), iron (III) chloride hexahydrate (reagent grade, $\geq 98 \%$ ), 1-octadecene (technical grade, $\geq 90 \%$ ), oleic acid (technical grade, $\geq 90 \%$ ), and PNDA ( $\geq 90 \%$ ) were purchased from Sigma-Aldrich (St. Louis, MO, USA) and used without further purification. Sodium oleate ( $\geq 97.0 \%)$ was purchased from TCI Chemicals. 1-Hexadecene (technical grade, $\geq 92 \%$ ), hexane (ACS grade, $\geq 99.5 \%$ ), and ethanol (ACS grade) were purchased from Fischer Scientific. Silicon wafers with 
$500 \mathrm{~nm} \pm 5 \%$ thermal oxide layer on top surface were purchased from University Wafer (South Boston, MA, USA). Ultrathin carbon type-A 400 mesh copper grids with lacey carbon for transmission electron microscopy (TEM) characterization were obtained from Ted Pella (Redding, CA, USA).

Characterization: Fourier transform infrared (FTIR) spectroscopy was used to analyze the aluminum oleate and iron oleate precursors as well as the synthesized nanoparticles. The sizes and shapes of the $\mathrm{Al}_{2} \mathrm{O}_{3}$ and $\mathrm{Fe}_{3} \mathrm{O}_{4}$ nanoparticles were characterized by atomic force microscopy (AFM; Bruker Dimension icon ScanAsyst AFM, Billerica, MA, USA), TEM (JEOL JEM-1230, Tokyo, Japan), and scanning electron microscopy (Philips FEI XL30 ESEM, North Billerica, MA, USA). X-ray photoelectron spectroscopy (XPS; K-Alpha, Thermo Scientific, Waltham, MA, USA) using a $400 \mu \mathrm{m}$ spot area was used to investigate the presence of linker molecules on metal oxide substrates. Raman spectroscopy using an inVia confocal Raman microscope (Renishaw, Gluocestershire, UK) with a $633 \mathrm{~nm}$ laser at $10 \%$ power was used to evaluate the quality of the grown nanotubes.

$\mathrm{Al}_{2} \mathrm{O}_{3}$ nanoparticle synthesis: $\mathrm{Al}_{2} \mathrm{O}_{3}$ nanoparticles were synthesized by the thermal decomposition of an aluminum oleate precursor in 1-octadecene as a high-boiling solvent. The aluminum oleate precursor was prepared by reacting $\mathrm{AlCl}_{3}(5 \mathrm{~g})$ and sodium oleate $(20 \mathrm{~g})$ in a solvent mixture $\left(70 \mathrm{~mL}\right.$ hexane $+40 \mathrm{~mL}$ ethanol $\left.+30 \mathrm{~mL} \mathrm{H}_{2} \mathrm{O}\right)$ for $4 \mathrm{~h}$ under reflux at $70{ }^{\circ} \mathrm{C}$ with continuous stirring [32]. Subsequently, $1.5 \mathrm{~g}(1.7 \mathrm{mmol})$ of aluminum oleate and $1.5 \mathrm{~mL}$ of oleic acid (as a capping agent) were dissolved in $50 \mathrm{~mL}$ of 1-octadecene. Using a three-neck boiling flask, this mixture was heated to $320^{\circ} \mathrm{C}$ for $2 \mathrm{~h}$ with continuous stirring. When the temperature was close to $320^{\circ} \mathrm{C}$, continuous bubbling was observed and the transparent solution became creamy white, indicating the nucleation of $\mathrm{Al}_{2} \mathrm{O}_{3}$ nanoparticles. After cooling to ambient temperature, the $\mathrm{Al}_{2} \mathrm{O}_{3}$ nanoparticles were precipitated using a 1:1 mixture of isopropyl alcohol and hexane. Subsequently, $\mathrm{Al}_{2} \mathrm{O}_{3}$ nanoparticles of different sizes were separated by centrifugation. The large-size oleic-acid-stabilized $\mathrm{Al}_{2} \mathrm{O}_{3}$ nanoparticles were first separated by centrifugation at $8000 \mathrm{rpm}$ for $60 \mathrm{~min}$, and then smaller $\mathrm{Al}_{2} \mathrm{O}_{3}$ nanoparticles were separated at 12,000 and 15,000 rpm for $60 \mathrm{~min}$. The $\mathrm{Al}_{2} \mathrm{O}_{3}$ nanoparticles were then redispersed in hexane or a hexane/isopropyl alcohol mixture (1:1) for further use.

$\mathrm{Fe}_{3} \mathrm{O}_{4}$ nanoparticle synthesis: $\mathrm{Fe}_{3} \mathrm{O}_{4}$ nanoparticles with uniform sizes were synthesized from an iron oleate precursor according to the procedure reported by Park et al. with some modifications [33]. Iron oleate $(1.5 \mathrm{~g}, 1.67 \mathrm{mmol})$ and oleic acid $(1.5 \mathrm{~mL})$ were dissolved in 1-hexadecene $(50 \mathrm{~mL})$. Using a three-neck boiling flask, the mixture was heated at $284^{\circ} \mathrm{C}$ for $60 \mathrm{~min}$ with continuous stirring under a nitrogen flow to control oxidation. The black solution was cooled to ambient temperature and $50 \mathrm{~mL}$ of ethanol was added to precipitate the $\mathrm{Fe}_{3} \mathrm{O}_{4}$ nanoparticles. Then, $\mathrm{Fe}_{3} \mathrm{O}_{4}$ nanoparticles of different sizes were separated by centrifugation and redispersed in hexane for further use [12,34].

Formation of $\mathrm{Al}_{2} \mathrm{O}_{3}$ nanoparticle monolayer: One side polished $\mathrm{SiO}_{2}$ layer (500 $\mathrm{nm} \pm 5 \%$ ) on one side of the silicon wafer was employed as a substrate for the synthesis of VA-CNTs. In order to form a monolayer of $\mathrm{Al}_{2} \mathrm{O}_{3}$ nanoparticles, the $\mathrm{SiO}_{2}$ substrate was modified with bifunctional PNDA using the procedure reported by Hanson et al. with some modifications [35]. A $3 \mathrm{~mm} \times 3 \mathrm{~mm}$ piece of one-side-polished $\mathrm{SiO}_{2}$ was cleaned by ultrasonication in acetone for $20 \mathrm{~min}$. The substrate was dried under a nitrogen flow and treated with piranha solution $\left(\mathrm{H}_{2} \mathrm{SO}_{4} / \mathrm{H}_{2} \mathrm{O}_{2}, 3: 1\right)$ for 30 min to generate hydroxyl groups on the surface [26,35]. After washing with water and drying under a nitrogen flow, the hydroxylated substrate was immersed in a solution of 2 mM PNDA in ethanol/water $(1: 1, \mathrm{v} / \mathrm{v})$ for $48 \mathrm{~h}$ to attach PNDA ligands to the surface. The substrate was washed with ethanol and an ethanol/water mixture (50:50). Subsequently, the substrate was immersed in a $3 \mathrm{mg} / \mathrm{mL}$ solution of oleic-acid-coated $\mathrm{Al}_{2} \mathrm{O}_{3}$ nanoparticles for $3 \mathrm{~h}$ to initiate a ligand exchange reaction between the terminal carboxylate group of PNDA and the carboxylate group of the oleic acid on the $\mathrm{Al}_{2} \mathrm{O}_{3}$ nanoparticle surface, thus forming a nanoparticle monolayer. Any physiosorbed particles were removed from the substrate surface by washing with hexane. 
Formation of $\mathrm{Fe}_{3} \mathrm{O}_{4}$ nanoparticle monolayer: $\mathrm{An} \mathrm{Fe}_{3} \mathrm{O}_{4}$ nanoparticle monolayer was formed on the $\mathrm{Al}_{2} \mathrm{O}_{3}$ nanoparticle layer using a similar procedure [21]. The substrate with the $\mathrm{Al}_{2} \mathrm{O}_{3}$ nanoparticle monolayer was annealed at $700{ }^{\circ} \mathrm{C}$ for $2 \mathrm{~h}$ to remove all of the organic ligands from the surface and to convert any aluminum hydroxide to $\mathrm{Al}_{2} \mathrm{O}_{3}$. Then, the substrate was treated with piranha solution and immersed in a $2 \mathrm{mM}$ PNDA solution to bind the linker molecules for the $\mathrm{Fe}_{3} \mathrm{O}_{4}$ monolayer formation. The substrate was immersed in an $\mathrm{Fe}_{3} \mathrm{O}_{4}$ nanoparticle solution to promote the ligand exchange reaction between the terminal carboxylate group of PNDA and the carboxylate group of oleic acid on the $\mathrm{Fe}_{3} \mathrm{O}_{4}$ nanoparticle surface. Optimized conditions ( $3 \mathrm{mg} / \mathrm{mL} \mathrm{Fe}_{3} \mathrm{O}_{4}$ nanoparticle solution for $3 \mathrm{~h}$ ) gave a compact monolayer of $\mathrm{Fe}_{3} \mathrm{O}_{4}$ nanoparticles. To remove any physiosorbed particles from the surface, the substrate was washed with hexane. The substrate was then heated at $400{ }^{\circ} \mathrm{C}$ for $1 \mathrm{~h}$ to remove the oleic acid capping agent and any other organics from the surface.

CNT synthesis: The CNTs were synthesized on the substrate with premade $\mathrm{Al}_{2} \mathrm{O}_{3}$ and $\mathrm{Fe}_{3} \mathrm{O}_{4}$ nanoparticle monolayers using CVD. Initially, the substrate was heated at $450{ }^{\circ} \mathrm{C}$ for $15 \mathrm{~min}$ in the presence of hydrogen in order to thermally reduce the $\mathrm{Fe}_{3} \mathrm{O}_{4}$ catalyst nanoparticles to metallic iron. Then, VA-CNTs were grown by CVD at $750{ }^{\circ} \mathrm{C}$ and atmospheric pressure for $20 \mathrm{~min}$ using acetylene as the carbon source with argon as the carrier gas.

\section{Results and Discussion}

The key aspect of this work was the monolayer assembly of premade $\mathrm{Fe}_{3} \mathrm{O}_{4}$ catalyst and $\mathrm{Al}_{2} \mathrm{O}_{3}$ catalyst support nanoparticles for the synthesis of VA-CNTs. It has been reported that the synthesis of CNTs with a specific chirality mostly depends on the interactions between the metal catalyst, catalyst support, and hydrocarbon [36-38]. Figure 1A shows a schematic diagram of the process for assembling the catalyst support and catalyst films for VA-CNT growth. Since $\mathrm{Al}_{2} \mathrm{O}_{3}$ is a common catalyst support for the large-scale synthesis of VA-CNTs, an $\mathrm{Al}_{2} \mathrm{O}_{3}$ film was prepared on the $\mathrm{SiO}_{2}$ surface by using premade $\mathrm{Al}_{2} \mathrm{O}_{3}$ nanoparticles in solution. The formation of the catalyst support monolayer required the $\mathrm{SiO}_{2}$ substrate to be activated by introducing hydroxyl groups that could be coupled with linker molecules. Subsequently, the $\mathrm{SiO}_{2}$ substate was modified with PNDA as an organic linker for binding nanoparticles. Organophosphonic acids have been widely used as ligands for metal oxide (e.g., $\mathrm{SiO}_{2}$ and $\mathrm{Al}_{2} \mathrm{O}_{3}$ ) functionalization in various applications, with the phosphonate group binding to the metal oxide substrate [39-42]. A similar approach using bifunctional PNDA to form a monolayer of iron-platinum bimetallic nanoparticles on an $\mathrm{Al}_{2} \mathrm{O}_{3}$ substrate indicated that the phosphonate and - $\mathrm{COOH}$ groups of PNDA were bound to the $\mathrm{Al}_{2} \mathrm{O}_{3}$ substrate and the nanoparticle surface, respectively [21]. The sequential formation of $\mathrm{Al}_{2} \mathrm{O}_{3}$ and $\mathrm{Fe}_{3} \mathrm{O}_{4}$ nanoparticle monolayers on the functionalized $\mathrm{SiO}_{2}$ substrate are shown in Figure 1B,C. Oleic acid on the nanoparticle surfaces facilitated the ligand exchange reaction using $-\mathrm{COOH}$ as an anchoring group [43].

The oleic-acid-coated $\mathrm{Al}_{2} \mathrm{O}_{3}$ nanoparticles that were synthesized from the aluminum oleate precursor were spherical, as shown in Figure $\mathrm{S} 1$. Larger $\mathrm{Al}_{2} \mathrm{O}_{3}$ nanoparticles were separated as the decant by centrifugation at 12,000 rpm for $60 \mathrm{~min}$ (Figure S1A), whereas comparatively small $\mathrm{Al}_{2} \mathrm{O}_{3}$ nanoparticles remained in the decanted solution (Figure $\mathrm{S1B}$ ), which were chosen to form the monolayer on the $\mathrm{SiO}_{2}$ substrate. FTIR spectroscopy was used to confirm the presence of an oleic acid coating on the surface of the $\mathrm{Al}_{2} \mathrm{O}_{3}$ nanoparticles (Figure S2). Characteristic bands associated with $-\mathrm{CH}_{2},-\mathrm{CH}$, and $\mathrm{C}=\mathrm{O}$ groups were observed for oleic acid (Figure S2A), aluminum oleate (Figure S2B), and the oleic-acid-coated $\mathrm{Al}_{2} \mathrm{O}_{3}$ nanoparticles (Figure S2C). The strong band at $1595 \mathrm{~cm}^{-1}$ in the FTIR spectrum of aluminum oleate (Figure S2B) corresponded to a COO-Al species [32], which is typically found at $1600 \mathrm{~cm}^{-1}$ [44]. The FTIR spectrum of oleic-acid-capped $\mathrm{Al}_{2} \mathrm{O}_{3}$ (Figure $\mathrm{S} 2 \mathrm{C}$ ) showed $\mathrm{C}-\mathrm{H}$ stretching peaks but no carbonyl peak. The strong peak at $\sim 1465 \mathrm{~cm}^{-1}$ and the peak at $\sim 1600 \mathrm{~cm}^{-1}$ (Figure S2C), which are characteristic of symmetric and asymmetric carboxylate (COO-) stretching, indicated that oleic acid was bound to the 
$\mathrm{Al}_{2} \mathrm{O}_{3}$ nanoparticle surface [45]. In addition, the appearance of a strong $-\mathrm{OH}$ stretching band at $3000-3600 \mathrm{~cm}^{-1}$ (Figure S2C) suggested the presence of hydroxylated $\mathrm{Al}_{2} \mathrm{O}_{3}$ particles. The FTIR spectrum of the $\mathrm{Al}_{2} \mathrm{O}_{3}$ nanoparticles that were annealed at $700{ }^{\circ} \mathrm{C}$ (Figure S2D) indicated that all of the organic functional groups, including oleic acid, were removed from the surface.

A)
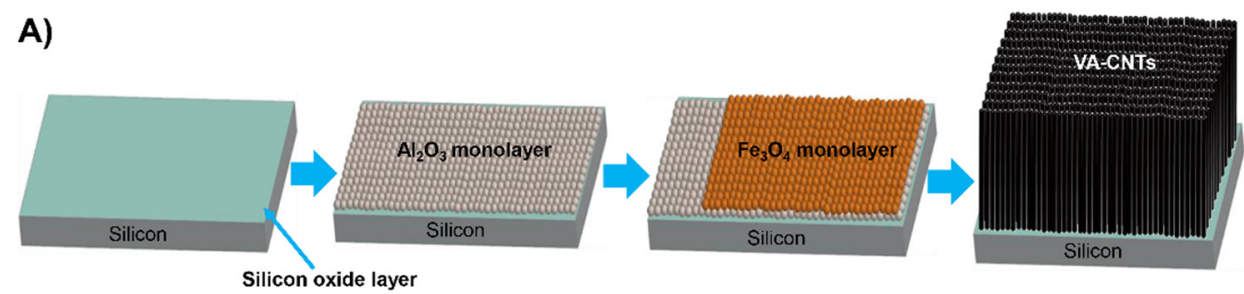

B)

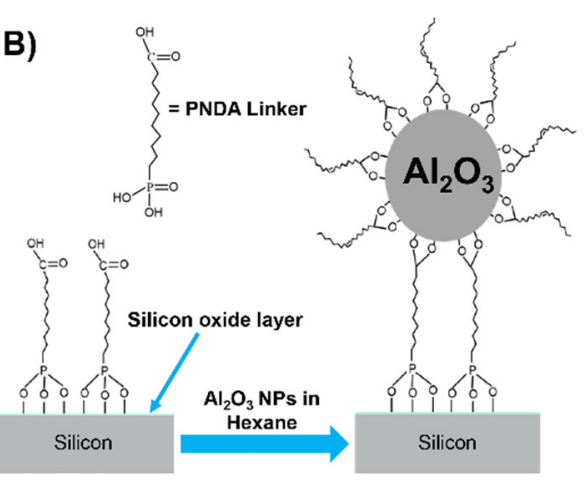

C)

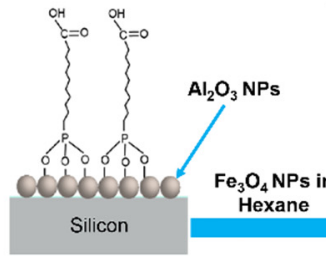

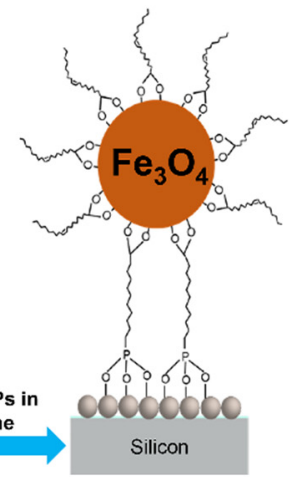

Figure 1. Schematic illustration of catalyst support and catalyst nanoparticle monolayer film assembly for the synthesis of VA-CNTs. (A) Step-wise formation of $\mathrm{Al}_{2} \mathrm{O}_{3}$ and $\mathrm{Fe}_{3} \mathrm{O}_{4}$ nanoparticle monolayers on a freshly cleaned $\mathrm{SiO}_{2}$ wafer. Schematic representations of (B) $\mathrm{Al}_{2} \mathrm{O}_{3}$ and (C) $\mathrm{Fe}_{3} \mathrm{O}_{4}$ nanoparticle monolayer assembly.

The sizes and shapes of the $\mathrm{Al}_{2} \mathrm{O}_{3}$ nanoparticles were characterized using $\mathrm{AFM}$ and TEM (Figure 2). Figure 2A shows an AFM image of the $\mathrm{Al}_{2} \mathrm{O}_{3}$ nanoparticles that were used for monolayer assembly as a catalyst support for VA-CNT growth. As shown by the particle size distribution (Figure 2B), the separated $\mathrm{Al}_{2} \mathrm{O}_{3}$ nanoparticles had an average size of $6.2 \pm 1.4 \mathrm{~nm}$. TEM characterization of the $\mathrm{Al}_{2} \mathrm{O}_{3}$ nanoparticles was performed before and after annealing (Figure 2C,D). TEM imaging of the oleic-acid-coated $\mathrm{Al}_{2} \mathrm{O}_{3}$ nanoparticles before annealing was difficult, likely because the organic coating or the hydroxylated nature of the nanoparticles interfered with the electron beam contrast. For the $\mathrm{Al}_{2} \mathrm{O}_{3}$ nanoparticles before annealing, the TEM sample was prepared by drop casting the nanoparticle solution on the TEM grid and subsequently baking the grid for 2 days at $70{ }^{\circ} \mathrm{C}$. As shown in Figure 2C, the $\mathrm{Al}_{2} \mathrm{O}_{3}$ nanoparticles before annealing were well distributed. For the $\mathrm{Al}_{2} \mathrm{O}_{3}$ nanoparticles after annealing at $700{ }^{\circ} \mathrm{C}$ for $2 \mathrm{~h}$, the nanoparticles were dispersed in isopropyl alcohol, the large $\mathrm{Al}_{2} \mathrm{O}_{3}$ nanoparticle aggregates were separated by centrifugation, and a few drops of $\mathrm{Al}_{2} \mathrm{O}_{3}$ nanoparticle solution were drop cast onto a copper grid for TEM characterization. As shown in Figure 2D, the $\mathrm{Al}_{2} \mathrm{O}_{3}$ nanoparticles, after annealing, showed some aggregation and distortion. XPS analysis was performed in order to confirm the elemental state of aluminum in the nanoparticles. Figure S3 shows the $\mathrm{Al} 2 \mathrm{p}$ and O1s core-level spectra. The Al2p peak at a binding energy of $74.3 \mathrm{eV}$ is consistent with the presence of $\mathrm{Al}_{2} \mathrm{O}_{3}$ in the nanoparticles [46]. The deconvoluted O1s peaks at 531 and $532.6 \mathrm{eV}$ indicated the presence of two different types of oxygen. The peak at $531 \mathrm{eV}$ corresponded to $\mathrm{Al}_{2} \mathrm{O}_{3}$, whereas the peak at $532.6 \mathrm{eV}$ could be due to dissolved oxygen (moisture) or hydroxyl groups in the sample [47,48]. Although these results indicate a high content of surface $-\mathrm{OH}$ groups on the $\mathrm{Al}_{2} \mathrm{O}_{3}$ nanoparticles, the high temperature used for CVD will convert them into oxides during the CNT synthesis process. 

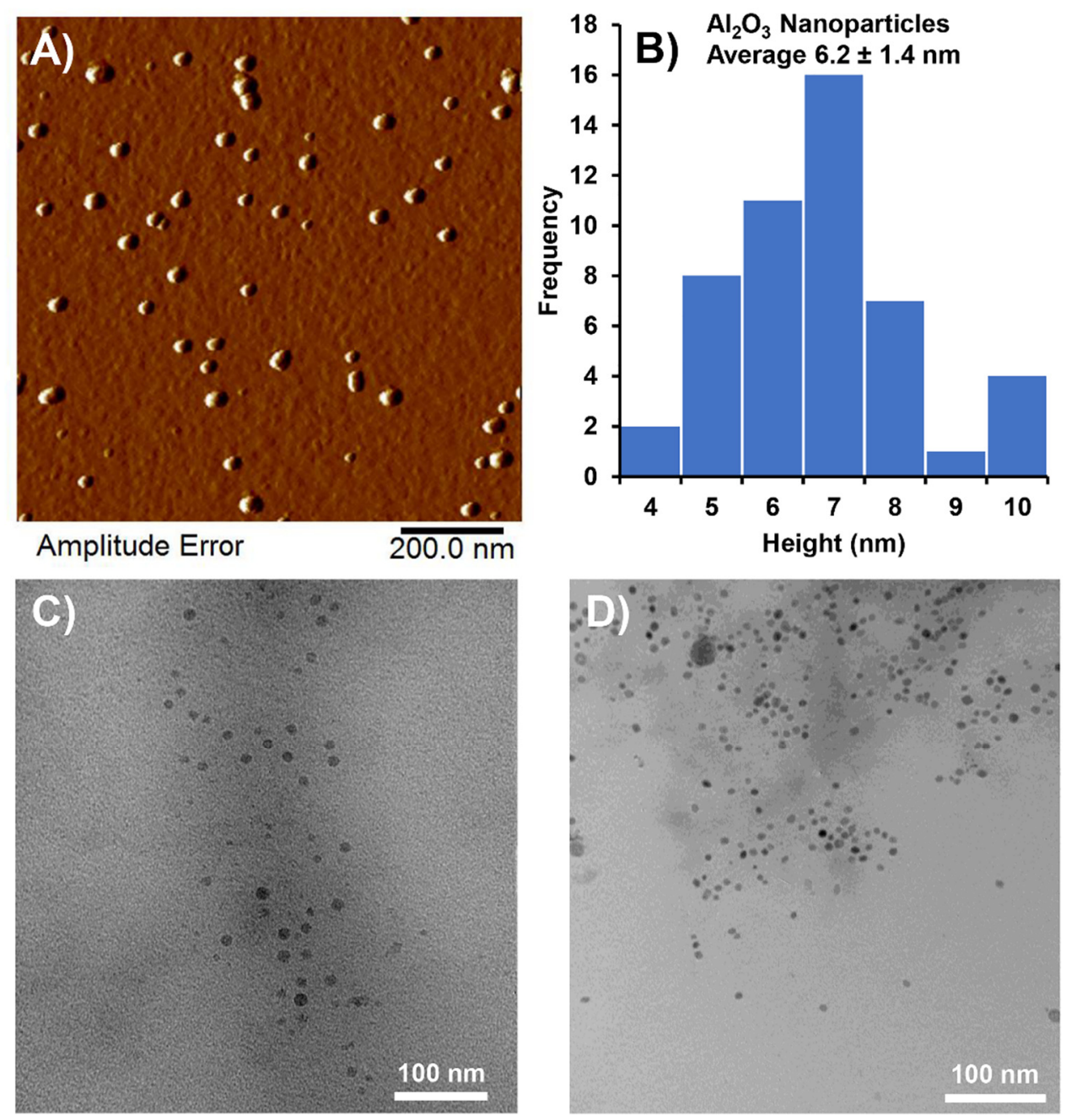

Figure 2. Characterization of synthesized $\mathrm{Al}_{2} \mathrm{O}_{3}$ nanoparticles. (A) AFM image of $\mathrm{Al}_{2} \mathrm{O}_{3}$ nanoparticles, (B) $\mathrm{Al}_{2} \mathrm{O}_{3}$ nanoparticle size distribution, (C) TEM image of $\mathrm{Al}_{2} \mathrm{O}_{3}$ nanoparticles before annealing, and (D) TEM image of $\mathrm{Al}_{2} \mathrm{O}_{3}$ nanoparticles after annealing at $700{ }^{\circ} \mathrm{C}$.

$\mathrm{Fe}_{3} \mathrm{O}_{4}$ nanoparticles were synthesized using iron oleate as a precursor and 1-hexadecene as a solvent, similar to the method reported by Park et al. [33]. The obtained oleic-acidstabilized $\mathrm{Fe}_{3} \mathrm{O}_{4}$ nanoparticles of different sizes were separated by centrifugation at various speeds. After removing the larger particles, the precipitate that was obtained at $8000 \mathrm{rpm}$ gave a relatively homogenous size distribution, as shown by the AFM image in Figure $3 \mathrm{~A}$ and the corresponding particle size distribution in Figure 3B. The $\mathrm{Fe}_{3} \mathrm{O}_{4}$ catalyst nanoparticles with an average size of $9.3 \pm 1.2 \mathrm{~nm}$ were chosen to form a monolayer on the $\mathrm{Al}_{2} \mathrm{O}_{3}$ film for VA-CNT growth. The low- and high-magnification TEM images in Figure 3C,D reveal that these $\mathrm{Fe}_{3} \mathrm{O}_{4}$ nanoparticles had relatively uniform sizes and shapes. FTIR spectral analysis was used to verify the presence of an oleic acid coating on the nanoparticle surface. As shown in Figure S4, the FTIR spectra of oleic acid, iron oleate, and the oleic-acidcoated $\mathrm{Fe}_{3} \mathrm{O}_{4}$ nanoparticles contained characteristic bands associated with $-\mathrm{CH}_{2},-\mathrm{CH}$, and $\mathrm{C}=\mathrm{O}$ groups. The characteristics asymmetric and symmetric $\mathrm{COO}-\mathrm{Al}$ bands at $\sim 1438$ and $\sim 1600 \mathrm{~cm}^{-1}$ (Figure S4B) confirm the prepared aluminum oleate precursor for the synthesis of $\mathrm{Fe}_{3} \mathrm{O}_{4}$ catalyst nanoparticles. For the oleic-acid-coated $\mathrm{Fe}_{3} \mathrm{O}_{4}$ nanoparticles, a strong $\mathrm{C}-\mathrm{H}$ stretching band appeared at $2850 \mathrm{~cm}^{-1}$, but the intensity of the carbonyl stretching band at $1710 \mathrm{~cm}^{-1}$ was reduced (Figure S4C). The characteristic asymmetric and symmetric stretching bands at $\sim 1438$ and $\sim 1600 \mathrm{~cm}^{-1}$ (Figure S4C), respectively, confirmed that oleic acid was chemisorbed on the $\mathrm{Fe}_{3} \mathrm{O}_{4}$ nanoparticles [49]. Although the $\mathrm{Fe}_{3} \mathrm{O}_{4}$ nanoparticles 
contained both $\gamma-\mathrm{Fe}_{2} \mathrm{O}_{3}$ and $\mathrm{Fe}_{3} \mathrm{O}_{4}$, the dominant phase was $\mathrm{Fe}_{3} \mathrm{O}_{4}$ based on the synthetic method that was used [33]. The liquid-phase synthesis of the catalyst nanoparticles provides direct control over particle size because oleic acid acts as a passivation layer to reduce nanoparticle aggregation [50]. In wet chemical processes, an oxygen-free environment and low synthesis temperature reduce the size of the obtained nanoparticles, whereas catalyst formation at high temperatures provides less control over particle size.
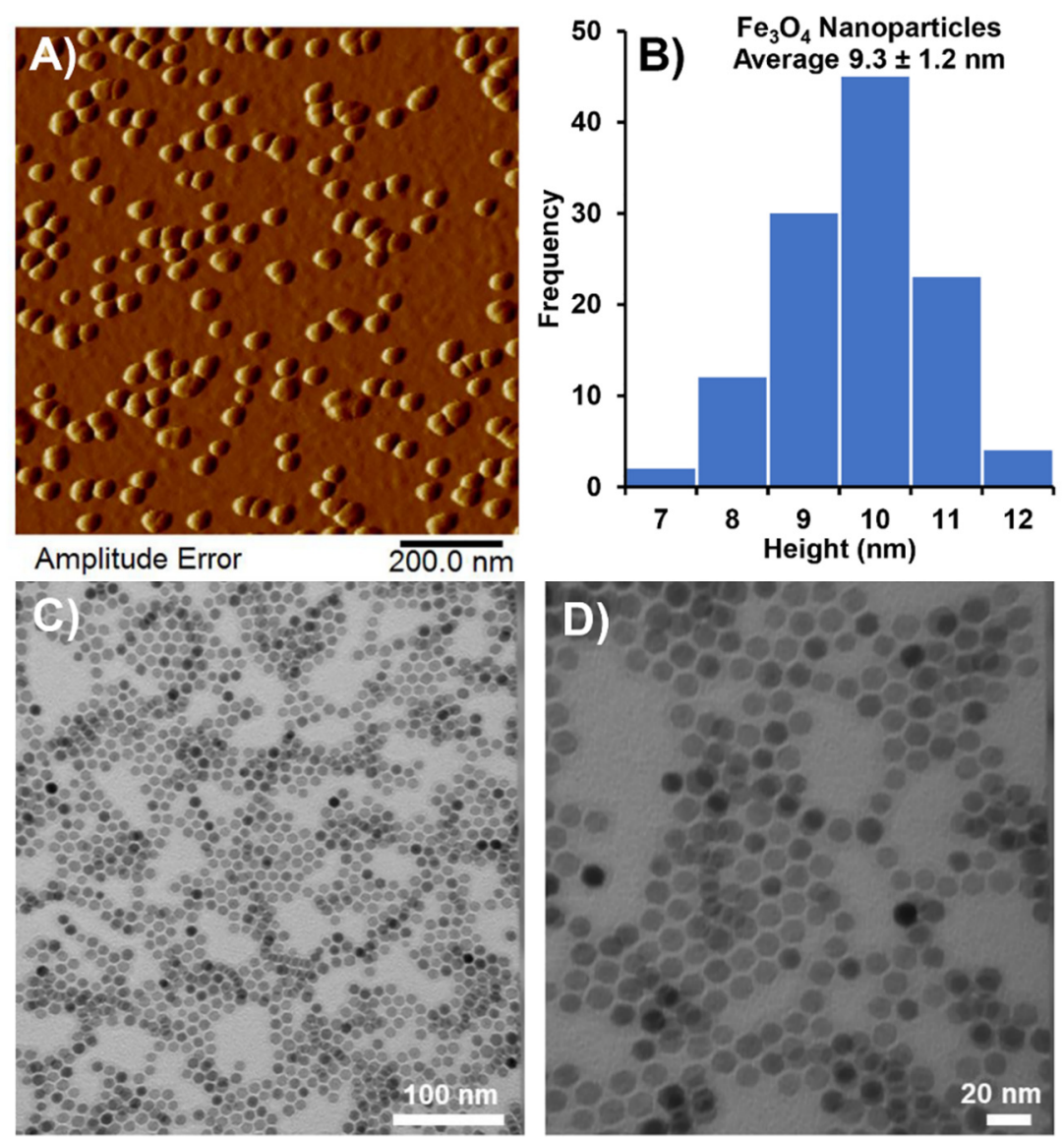

Figure 3. Characterization of synthesized $\mathrm{Fe}_{3} \mathrm{O}_{4}$ nanoparticles. (A) AFM image of $\mathrm{Fe}_{3} \mathrm{O}_{4}$ nanoparticles, (B) $\mathrm{Fe}_{3} \mathrm{O}_{4}$ nanoparticle size distribution, (C) low-magnification TEM image of $\mathrm{Fe}_{3} \mathrm{O}_{4}$ nanoparticles, and (D) high-magnification TEM image of $\mathrm{Fe}_{3} \mathrm{O}_{4}$ nanoparticles.

The use of catalyst nanoparticle dispersions with uniform sizes for the assembly of monolayer films could provide improved control over CNT characteristics. Importantly, as this approach is less expensive than traditional catalyst preparation processes, scalable VACNT growth can be realized. Bifunctional or multifunctional molecules can be employed as linkers on substrates/surfaces depending on the strength of the interaction between the functional group and substrate. Surface hydroxyl $(-\mathrm{OH})$ groups on $\mathrm{SiO}_{2}$ and $\mathrm{Al}_{2} \mathrm{O}_{3}$ generated by piranha treatment can enhance the reactivity toward linker molecules [51]. The condensation reaction between the hydroxyl group of a silanol and the phosphonic acid group of PNDA produced a phosphonate group that was bound to the substrate surface and $\mathrm{H}_{2} \mathrm{O}$ as a byproduct $[35,52]$. Phosphonate groups have a higher grafting rate and stronger binding ability with metal oxide substrates than carboxylate groups [53]. The XPS analysis was conducted to confirm the functionalization of silicon oxide substrate with PNDA ligand. Figures S5 and S6 show the XPS survey spectra of the bare $\mathrm{SiO}_{2}$ substrate and the $\mathrm{SiO}_{2}$ substrate with bound phosphonate groups (PNDA), which were compared to reference XPS spectra [54]. The core-level Si2p, P2p, O1s, and C1s spectra are shown in Figure S7. The P2p peak at a binding energy of $132.9 \mathrm{eV}$ confirmed the successful binding of phosphonate to the $\mathrm{SiO}_{2}$ substrate. 
An $\mathrm{Al}_{2} \mathrm{O}_{3}$ nanoparticle monolayer was formed on the PNDA-functionalized $\mathrm{SiO}_{2}$ substrate via a ligand exchange reaction in an $\mathrm{Al}_{2} \mathrm{O}_{3}$ nanoparticle solution. The carboxylate $(\mathrm{COOH})$ group of the PNDA linker on the $\mathrm{SiO}_{2}$ substrate was exchanged with the $\mathrm{COOH}$ group of oleic acid on the $\mathrm{Al}_{2} \mathrm{O}_{3}$ nanoparticle surface [21]. After the successful $\mathrm{Al}_{2} \mathrm{O}_{3}$ monolayer formation, the substrate was dried at $400^{\circ} \mathrm{C}$ for $1 \mathrm{~h}$ and characterized by AFM in tapping mode (Figure 4). The surface morphology of the bare $\mathrm{SiO}_{2}$ substrate (Figure $4 \mathrm{~A}$ ) was very smooth with no particles, whereas the $\mathrm{Al}_{2} \mathrm{O}_{3}$ nanoparticle assembly (Figure $4 \mathrm{~B}$ ) exhibited well-distributed nanoparticles on the surface. The cross-sectional profile of the bare $\mathrm{SiO}_{2}$ substrate (Figure $4 \mathrm{C}$ ) showed that the substrate was almost planar with a height variation of $\sim 0.5 \mathrm{~nm}$. In contrast, the cross-sectional profile of the $\mathrm{Al}_{2} \mathrm{O}_{3}$ nanoparticle assembly (Figure $4 \mathrm{D}$ ) showed a nanoparticle layer with a height variation of $\sim 5 \mathrm{~nm}$, which is similar to the average size of the $\mathrm{Al}_{2} \mathrm{O}_{3}$ nanoparticles that were used for monolayer formation. Thus, the liquid-phase preparation of an $\mathrm{Al}_{2} \mathrm{O}_{3}$ catalyst support via monolayer assembly is suitable for the development of an easy and inexpensive method for the largescale synthesis of VA-CNTs. The $\mathrm{Al}_{2} \mathrm{O}_{3}$ film was annealed at $700{ }^{\circ} \mathrm{C}$ for $2 \mathrm{~h}$ to remove all of the organic molecules (capping agents and surface ligands) from the surface and convert any aluminum hydroxide to the oxide for application as a catalyst support.
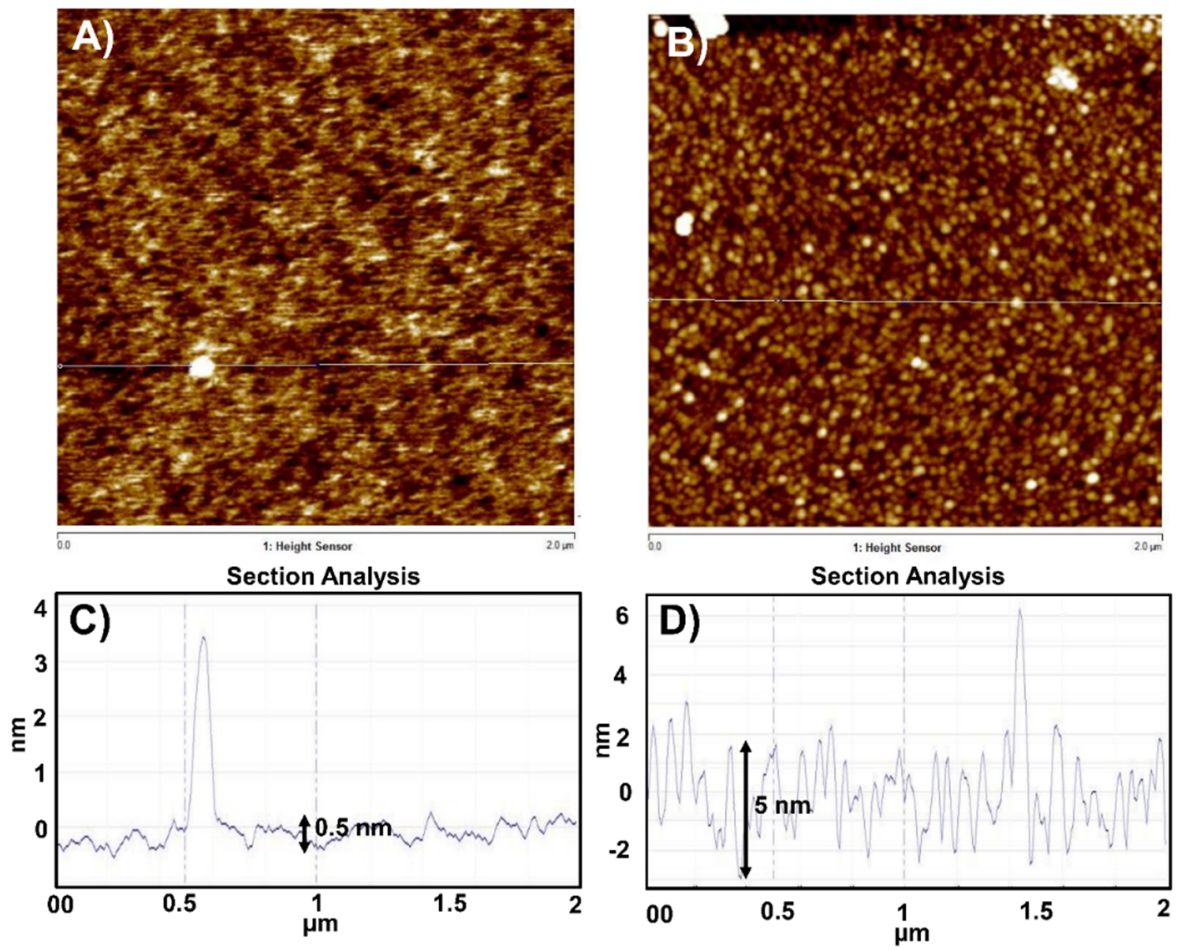

Figure 4. Surface morphology of the $\mathrm{SiO}_{2}$ substrate before and after assembly of the $\mathrm{Al}_{2} \mathrm{O}_{3}$ nanoparticle monolayer. AFM images of (A) the bare $\mathrm{SiO}_{2}$ substrate and (B) the $\mathrm{Al}_{2} \mathrm{O}_{3}$ nanoparticle monolayer. Height cross-sectional profiles (surface roughness) of (C) the bare $\mathrm{SiO}_{2}$ substrate and (D) the $\mathrm{Al}_{2} \mathrm{O}_{3}$ nanoparticle monolayer.

$\mathrm{Al}_{2} \mathrm{O}_{3}$ interacts strongly with iron, which can reduce the aggregation of catalyst particles on the substrate. Thus, an $\mathrm{Fe}_{3} \mathrm{O}_{4}$ monolayer was formed over the $\mathrm{Al}_{2} \mathrm{O}_{3}$ layer, which was modified with PNDA using a procedure similar to that for the $\mathrm{SiO}_{2}$ substrate. The successful binding of PNDA on the $\mathrm{Al}_{2} \mathrm{O}_{3}$ monolayer was confirmed by XPS. The XPS survey spectrum of the PNDA film on the $\mathrm{Al}_{2} \mathrm{O}_{3}$ layer (Figure S8) showed all the core-level peaks of $\mathrm{Al}_{2} \mathrm{O}_{3}$ as well as a phosphorous peak. The Al2p, P2p, O1s, and C1s core-level spectra of PNDA on the $\mathrm{Al}_{2} \mathrm{O}_{3}$ layer are shown in Figure S9. The three peaks in the $\mathrm{C} 1 \mathrm{~s}$ spectrum confirmed the presence of carboxylate functionalities on the $\mathrm{Al}_{2} \mathrm{O}_{3}$ substrate [55]. The $\mathrm{C} 1 \mathrm{~s}$ peak at $284.5 \mathrm{eV}$ corresponded to regular carbon $\left(\mathrm{CH}, \mathrm{CH}_{2}\right)$, whereas the peaks at 285.5 and $289 \mathrm{eV}$ corresponded to carbon in the carbonyl (CO) and 
carboxylate $(\mathrm{COOH})$ groups, respectively. A monolayer of $\mathrm{Fe}_{3} \mathrm{O}_{4}$ catalyst nanoparticles was formed on the $\mathrm{Al}_{2} \mathrm{O}_{3}$ layer via the ligand exchange reaction between the $\mathrm{COOH}$ groups of the PNDA linker on the functionalized $\mathrm{Al}_{2} \mathrm{O}_{3}$ surface and the $\mathrm{COOH}$ group of oleic acid on the $\mathrm{Fe}_{3} \mathrm{O}_{4}$ nanoparticles in solution. The low- $(15 \mu \mathrm{m} \times 15 \mu \mathrm{m})$ and high-magnification AFM images $(2 \mu \mathrm{m} \times 2 \mu \mathrm{m})$ of the $\mathrm{Fe}_{3} \mathrm{O}_{4}$ monolayer (Figure $5 \mathrm{~A}, \mathrm{~B}$ ) indicated that a compact nanoparticle layer was formed containing nanoparticles of a uniform size. The corresponding cross-sectional profiles of the AFM images (Figure 5C,D) revealed small openings in the monolayer assembly with heights of approximately 10 $\mathrm{nm}$, which is consistent with the average size of the $\mathrm{Fe}_{3} \mathrm{O}_{4}$ nanoparticles that were used for monolayer formation $(9.3 \pm 1.2 \mathrm{~nm})$. The surface functionalization of metal oxide substrates with monolayers or multilayers of $\mathrm{Fe}_{3} \mathrm{O}_{4}$ nanoparticles has been studied for various applications [18]. However, $\mathrm{Fe}_{3} \mathrm{O}_{4}$ nanoparticle monolayers are expected to be suitable as catalysts for VA-CNT growth because the high density and uniformity of catalyst particles can provide control over the number of nanotubes formed in a specific area, as well as their diameters. The density of the $\mathrm{Fe}_{3} \mathrm{O}_{4}$ nanoparticles on the $\mathrm{Al}_{2} \mathrm{O}_{3}$ layer was $1.4 \times 10^{11}$ nanoparticles $/ \mathrm{cm}^{2}$, which was determined by counting the nanoparticles using a high-magnification $(100 \mathrm{~nm} \times 100 \mathrm{~nm}) \mathrm{AFM}$ image. The number of total $\mathrm{Fe}_{3} \mathrm{O}_{4}$ nanoparticles were manually counted in a $100 \times 100 \mathrm{~nm}^{2}$ area and their density was extrapolated for a square centimeter area. In addition, the use of a monolayer of uniform catalyst nanoparticles can reduce particle aggregation and catalyst poisoning.
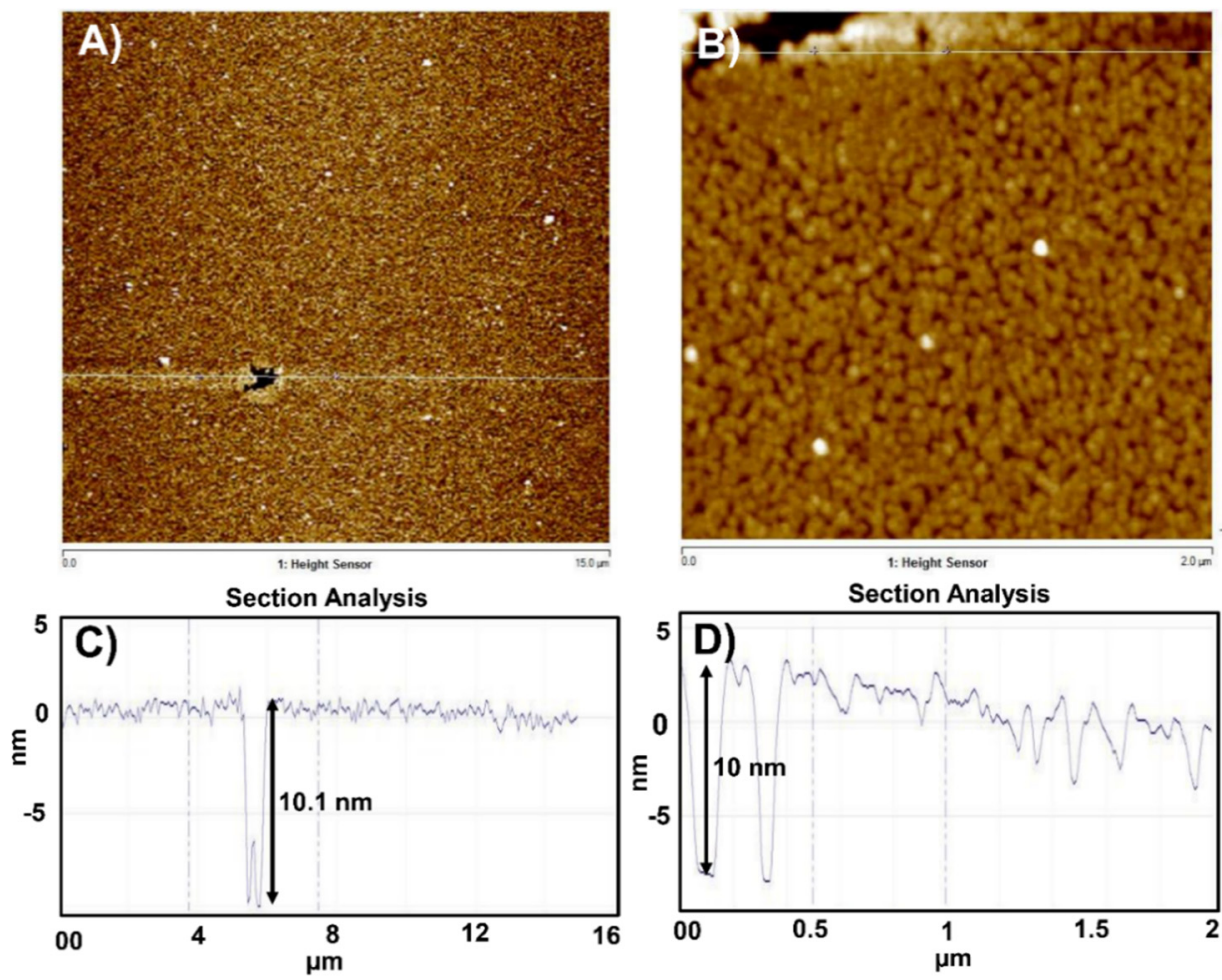

Figure 5. Surface morphology of the $\mathrm{Fe}_{3} \mathrm{O}_{4}$ nanoparticle monolayer formed over the $\mathrm{Al}_{2} \mathrm{O}_{3}$ monolayer film. (A) Low-magnification $(15 \mu \mathrm{m} \times 15 \mu \mathrm{m})$ and (B) high-magnification $(2 \mu \mathrm{m} \times 2 \mu \mathrm{m})$ AFM images of the $\mathrm{Fe}_{3} \mathrm{O}_{4}$ nanoparticle monolayer. Height cross-sectional profiles corresponding to (C) image $\mathrm{A}$ and (D) image $\mathrm{B}$.

Using the premade monolayer of catalyst nanoparticles, CNTs were synthesized by CVD, which is a suitable technique for large-scale synthesis. First, all of the organics were removed from the catalyst surface by heating at $400{ }^{\circ} \mathrm{C}$ for $2 \mathrm{~h}$ in the open air. Subsequently, the $\mathrm{Fe}_{3} \mathrm{O}_{4}$ monolayer was reduced to metallic iron by thermal reduction at $450{ }^{\circ} \mathrm{C}$ for 15 min using atomic hydrogen $(\mathrm{H})$ generated from a hydrogen gas $\left(\mathrm{H}_{2}\right)$ flow [56]. VACNTs were successfully synthesized using acetylene as a carbon precursor at $750{ }^{\circ} \mathrm{C}$ for 
$15 \mathrm{~min}$. A comparative literature study about synthesis methods of vertically aligned CNTs from premade nanoparticles is shown in supplementary information (Table S1). The table compares different methodologies used for assembly of catalyst nanoparticles for CNTs growth. Figure 6A,B show low- and high-magnification SEM images of the grown VA-CNTs where uniform-length of CNTs are observed. Though the density of catalyst nanoparticles in Figure 5B is quite very high, the lower density of CNTs growth can be the result of lower nucleation rates of catalyst particles. Authors think that investigating the suitable synthesis parameters in CVD reaction can increase the nucleation rates which can increase the density of VACNTs. TEM imaging (Figure 6C) indicated that the CNTs that were grown from the catalyst nanoparticle monolayer had relatively similar diameters. The quality of the grown CNTs was assessed using Raman spectral analysis (Figure 6D). The characteristic $\mathrm{G}$ peak of CNTs, which corresponds to $\mathrm{sp}^{2}$ carbon, was more prominent than the $\mathrm{D}$ peak, which corresponds to $\mathrm{sp}^{3}$ carbon, indicating the structural defects of CNTs, which are typical of multilayer CNTs. A small RBM peak was also observed in the Raman spectrum of the VA-CNTs, which indicated the presence of a few single-walled CNTs among the mostly multi-walled CNTs.
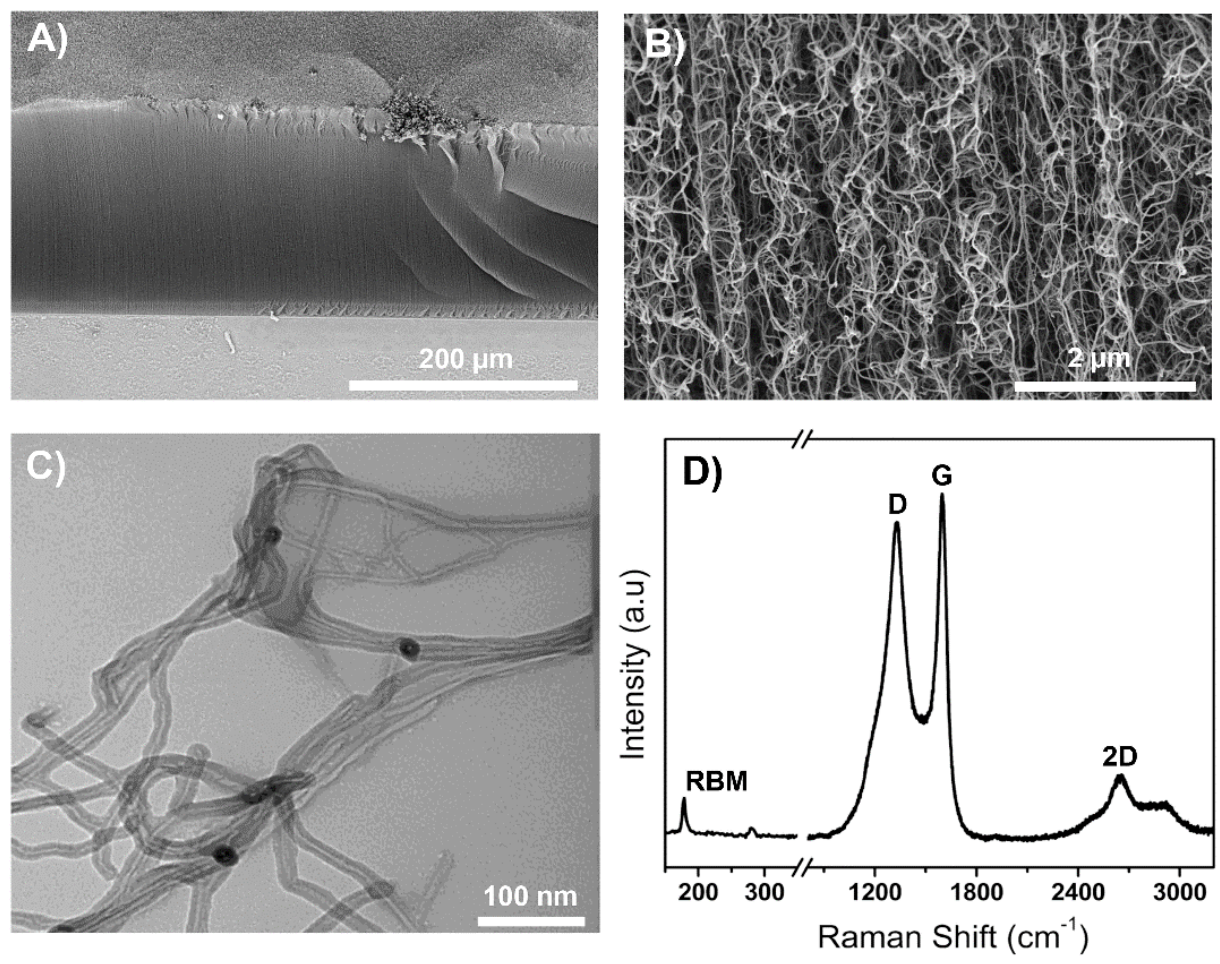

Figure 6. Characterization of VA-CNTs grown from the premade nanoparticle monolayer assembly. (A) Low-magnification SEM image, (B) high-magnification SEM image, (C) high-magnification TEM image, and (D) Raman spectrum of VA-CNTs.

\section{Conclusions}

Spherical $\mathrm{Al}_{2} \mathrm{O}_{3}$ and $\mathrm{Fe}_{3} \mathrm{O}_{4}$ nanoparticles were synthesized and separated into different sizes by varying the centrifugation speed, which provided sufficiently homogenous nanoparticles with which to form monolayer films. Using wet chemical processes, continuous monolayer films of $\mathrm{Al}_{2} \mathrm{O}_{3}$ nanoparticles as a catalyst support and $\mathrm{Fe}_{3} \mathrm{O}_{4}$ nanoparticles as a catalyst were sequentially assembled on an $\mathrm{SiO}_{2}$ substrate using PNDA as a linker molecule. This monolayer assembly was successfully applied to catalyze the growth of uniform, high-density VA-CNTs. This approach for preparing a catalyst support monolayer using premade $\mathrm{Al}_{2} \mathrm{O}_{3}$ nanoparticles provides an inexpensive and easy alternative to the conventional methods for fabricating thin film catalyst supports such as sputtering, e-beam deposition, and other instrumentation that requires ultrahigh vacuum systems. 
Furthermore, the use of a catalyst particle monolayer can improve the homogeneity of the obtained CNTs and increase CNT density.

Supplementary Materials: The following are available online at https://www.mdpi.com/article/ 10.3390/c7040079/s1, Table S1: Current methods of premade catalyst nanoparticles assembly used for CNTs growth; Figure S1: SEM images of spherical shaped aluminum oxide/hydroxide NPs. (A) Large size of aluminum oxide/hydroxide nanoparticles separated by centrifuge technique with 12,000 rpm, (B) Small size of nanoparticles remained in decanted solution. A few drops of nanoparticle solution was drop cast onto a silicon wafer and annealed at $400{ }^{\circ} \mathrm{C}$ for an hour before characterization; Figure S2: FTIR spectra of (A) pure oleic acid, (B) aluminum oleate, (C) aluminum oxide nanoparticles without annealing, and (D) aluminum oxide nanoparticles annealed at $700{ }^{\circ} \mathrm{C}$; Figure S3: XPS spectra of aluminum oxide nanoparticles after annealing at $700{ }^{\circ} \mathrm{C}$ for $2 \mathrm{~h}$. (A) Survey spectra that represent all the core level peaks, (B) Al 2p, and (C) O 1s; Figure S4: FTIR spectra of (A) pure oleic acid, (B) iron oleate, and (C) oleic acid coated iron oxide nanoparticles; Figure S5: XPS survey spectra of blank silicon oxide substrate that show all the core level peaks; Figure S6: XPS survey spectra of 11-phosphonoundecanoic acid (PNDA) film on silicon substrate showing all core level peaks; Figure S7: XPS spectra of PNDA attached silicon oxide substrate. (A) core level Si 2p peak, (B) core level P 2p peak, (C) core level O 1s peak, and (D) core level C 1s peak; Figure S8: XPS survey spectra of 11-phosphonoundecanoic acid film on alumina monolayer showing all core level peaks; Figure S9: XPS spectra of PNDA attached aluminum oxide substrate. (A) core level Al 2p peak, (B) core level P 2p peak, (C) core level O 1s peak, and (D) core level C 1s peak.

Author Contributions: Conceptualization, methodology, validation, N.T.A. and A.H.; formal analysis, A.H.; investigation, A.H., A.U. and B.S.G.; resources, supervision, project administration, N.T.A.; writing — original draft preparation, A.H.; writing—review and editing, A.H. and N.T.A.; funding acquisition, N.T.A. All authors have read and agreed to the published version of the manuscript.

Funding: This research was funded by NSF, grant number 2016484 under NSF PFI-RP.

Acknowledgments: The authors are thankful for professorship start-up funds from the Department of Chemistry at the University of Cincinnati. Partial salary support for A.U. was provided by an internal seed grant from the University of Kentucky (UK) Energy Research Priority Area program. XPS data were collected at the UK electron microscopy center (EMC), which belongs to the National Science Foundation NNCI Kentucky Multiscale Manufacturing and Nano Integration Node, supported by ECCS-1542174.

Conflicts of Interest: The authors declare no conflict of interest. The funders had no role in the design of the study; in the collection, analyses, or interpretation of data; in the writing of the manuscript, or in the decision to publish the results.

\section{References}

1. Alvarez, N.T.; Miller, P.; Haase, M.; Kienzle, N.; Zhang, L.; Schulz, M.J.; Shanov, V. Carbon Nanotube Assembly at Near-Industrial Natural-Fiber Spinning Rates. Carbon 2015, 86, 350-357. [CrossRef]

2. Alvarez, N.T.; Miller, P.; Haase, M.R.; Lobo, R.; Malik, R.; Shanov, V. Tailoring Physical Properties of Carbon Nanotube Threads during Assembly. Carbon 2019, 144, 55-62. [CrossRef]

3. Amama, P.B.; Pint, C.L.; Kim, S.M.; Eyink, K.G.; Stach, E.A.; Hauge, R.H.; Maruyama, B. Evolution, Activity, and Lifetime of Alumina-Supported Fe Catalyst during Super Growth of Single-Walled Carbon Nanotube Carpets: Influence of the Type of Alumina. Mater. Res. Soc. Symp. Proc. 2010, 1258, 217-222. [CrossRef]

4. Modekwe, H.U.; Mamo, M.A.; Moothi, K.; Daramola, M.O. Effect of Different Catalyst Supports on the Quality, Yield and Morphology of Carbon Nanotubes Produced from Waste Polypropylene Plastics. Catalysts 2021, 11, 692. [CrossRef]

5. Wang, B.; Yang, Y.; Li, L.J.; Chen, Y. Effect of Different Catalyst Supports on the (n,m) Selective Growth of Single-Walled Carbon Nanotube from Co-Mo Catalyst. J. Mater. Sci. 2009, 44, 3285-3295. [CrossRef]

6. Christen, H.M.; Puretzky, A.A.; Cui, H.; Belay, K.; Fleming, P.H.; Geohegan, D.B.; Lowndes, D.H. Rapid Growth of Long, Vertically Aligned Carbon Nanotubes through Efficient Catalyst Optimization Using Metal Film Gradients. Nano Lett. 2004, 4, 1939-1942. [CrossRef]

7. Guzmán De Villoria, R.; Figueredo, S.L.; Hart, A.J.; Steiner, S.A.; Slocum, A.H.; Wardle, B.L. High-Yield Growth of Vertically Aligned Carbon Nanotubes on a Continuously Moving Substrate. Nanotechnology 2009, 20, 1-8. [CrossRef]

8. Pint, C.L.; Kim, S.M.; Stach, E.A.; Hauge, R.H. Rapid and Scalable Reduction of Dense Surface-Supported Metal-Oxide Catalyst with Hydrazine Vapor. ACS Nano 2009, 3, 1897-1905. [CrossRef] 
9. Cheung, C.L.; Kurtz, A.; Park, H.; Lieber, C.M. Diameter-Controlled Synthesis of Carbon Nanotubes. J. Phys. Chem. B 2002, 106, 2429-2433. [CrossRef]

10. Kukovitsky, E.F.; L'vov, S.G.; Sainov, N.A.; Shustov, V.A.; Chernozatonskii, L.A. Correlation between Metal Catalyst Particle Size and Carbon Nanotube Growth. Chem. Phys. Lett. 2002, 355, 497-503. [CrossRef]

11. Sinnott, S.B.; Andrews, R.; Qian, D.; Rao, A.M.; Mao, Z.; Dickey, E.C.; Derbyshire, F. Model of Carbon Nanotube Growth through Chemical Vapor Deposition. Chem. Phys. Lett. 1999, 315, 25-30. [CrossRef]

12. Alvarez, N.T.; Li, F.; Pint, C.L.; Mayo, J.T.; Fisher, E.Z.; Tour, J.M.; Colvin, V.L.; Hauge, R.H. Uniform Large Diameter Carbon Nanotubes in Vertical Arrays from Premade Near-Monodisperse Nanoparticles. Chem. Mater. 2011, 23, 3466-3475. [CrossRef]

13. Schäffel, F.; Kramberger, C.; Rümmeli, M.H.; Grimm, D.; Mohn, E.; Gemming, T.; Pichler, T.; Rellinghaus, B.; Büchner, B.; Schultz, L. Nanoengineered Catalyst Particles as a Key for Tailor-Made Carbon Nanotubes. Chem. Mater. 2007, 19, 5006-5009. [CrossRef]

14. Alvarez, N.T.; Orbaek, A.; Barron, A.R.; Tour, J.M.; Hauge, R.H. Dendrimer-Assisted Self-Assembled Monolayer of Iron Nanoparticles for Vertical Array Carbon Nanotube Growth. ACS Appl. Mater. Interfaces 2010, 2, 15-18. [CrossRef]

15. Alvarez, N.T.; Hamilton, C.E.; Pint, C.L.; Orbaek, A.; Yao, J.; Frosinini, A.L.; Barron, A.R.; Tour, J.M.; Hauge, R.H. Wet CatalystSupport Films for Production of Vertically Aligned Carbon Nanotubes. ACS Appl. Mater. Interfaces 2010, 2, 1851-1856. [CrossRef]

16. Yang, Z.; Zhang, S.; Li, L.; Chen, W. Research Progress on Large-Area Perovskite Thin Fi Lms and Solar Modules. J. Mater. 2017, 3, 231-244. [CrossRef]

17. Chen, J.; Xu, X.; Zhang, L.; Huang, S. Controlling the Diameter of Single-Walled Carbon Nanotubes by Improving the Dispersion of the Uniform Catalyst Nanoparticles on Substrate. Nano-Micro Lett. 2015, 7, 353-359. [CrossRef]

18. Pauly, M.; Pichon, B.P.; Albouy, P.A.; Fleutot, S.; Leuvrey, C.; Trassin, M.; Gallani, J.L.; Begin-Colin, S. Monolayer and Multilayer Assemblies of Spherically and Cubic-Shaped Iron Oxide Nanoparticles. J. Mater. Chem. 2011, 21, 16018-16027. [CrossRef]

19. Amama, P.B.; Pint, C.L.; McJilton, L.; Kim, S.M.; Stach, E.A.; Murray, P.T.; Hauge, R.H.; Maruyama, B. Role of Water in Super Growth of Single-Walled Carbon Nanotube Carpets. Nano Lett. 2009, 9, 44-49. [CrossRef]

20. Hasnan, N.S.N.; Timmiati, S.N.; Lim, K.L.; Yaakob, Z.; Kamaruddin, N.H.N.; Teh, L.P. Recent Developments in Methane Decomposition over Heterogeneous Catalysts: An Overview. Mater. Renew. Sustain. Energy 2020, 9, 1-18. [CrossRef]

21. Yildirim, O.; Gang, T.; Kinge, S.; Reinhoudt, D.N.; Blank, D.H.A.; van der Wiel, W.G.; Rijnders, G.; Huskens, J. Monolayer-Directed Assembly and Magnetic Properties of FePt Nanoparticles on Patterned Aluminum Oxide. Int. J. Mol. Sci. 2010, 11, 1162-1179. [CrossRef] [PubMed]

22. Andryszewski, T.; Iwan, M.; Hołdyński, M.; Fiałkowski, M. Synthesis of a Free-Standing Monolayer of Covalently Bonded Gold Nanoparticles. Chem. Mater. 2016, 28, 5304-5313. [CrossRef]

23. Feichtenschlager, B.; Lomoschitz, C.J.; Kickelbick, G. Tuning the Self-Assembled Monolayer Formation on Nanoparticle Surfaces with Different Curvatures: Investigations on Spherical Silica Particles and Plane-Crystal-Shaped Zirconia Particles. J. Colloid Interface Sci. 2011, 360, 15-25. [CrossRef]

24. Tizazu, G. A Simple Method for Patterning Nanoparticles on Planar Surfaces. J. Nanotechnol. 2019, 2019, 1-7. [CrossRef]

25. Karade, V.C.; Sharma, A.; Dhavale, R.P.; Dhavale, R.P.; Shingte, S.R.; Patil, P.S.; Kim, J.H.; Zahn, D.R.T.; Chougale, A.D.; Salvan, G.; et al. APTES Monolayer Coverage on Self-Assembled Magnetic Nanospheres for Controlled Release of Anticancer Drug Nintedanib. Sci. Rep. 2021, 11, 1-12. [CrossRef]

26. Acres, R.G.; Ellis, A.V.; Alvino, J.; Lenahan, C.E.; Khodakov, D.A.; Metha, G.F.; Andersson, G.G. Molecular Structure of 3Aminopropyltriethoxysilane Layers Formed on Silanol-Terminated Silicon Surfaces. J. Phys. Chem. C 2012, 116, 6289-6297. [CrossRef]

27. Zhou, M.; Hedlund, J. Assembly of Oriented Iron Oxide and Zeolite Crystals via Biopolymer Films. J. Mater. Chem. 2012, 22, 24877-24881. [CrossRef]

28. Wah, F.; Mun, L.; Tai, F.; Bee, S.; Hamid, A. Iron Oxide Nanoparticles Decorated Oleic Acid for High Colloidal Stability. Adv. Polym. Technol. 2017, 37, 1712-1721. [CrossRef]

29. Tamaki, H.; Abe, S.; Yamagata, S.; Yoshida, Y.; Sato, Y. Self-Assembled Monolayer Formation on a Dental Orthodontic Stainless Steel Wire Surface to Suppress Metal Ion Elution. Coatings 2020, 10, 367. [CrossRef]

30. Yamada, K.; Kaneko, A.; Kato, H.; Homma, Y. Vertically-Aligned Carbon Nanotube Growth Using Closely Packed Iron Oxide Nanoparticles. Mater. Express 2012, 2, 257-260. [CrossRef]

31. Signore, M.A.; Rizzo, A.; Rossi, R.; Piscopiello, E.; Di Luccio, T.; Capodieci, L.; Dikonimos, T.; Giorgi, R. Role of Iron Catalyst Particles Density in the Growth of Forest-like Carbon Nanotubes. Diam. Relat. Mater. 2008, 17, 1936-1942. [CrossRef]

32. Lee, D.H.; Condrate, R.A. FTIR Spectral Characterization of Thin Film Coatings of Oleic Acid on Glasses: I. Coatings on Glasses from Ethyl Alcohol. J. Mater. Sci. 1999, 34, 139-146. [CrossRef]

33. Park, J.; An, K.; Hwang, Y.; Park, J.E.G.; Noh, H.J.; Kim, J.Y.; Park, J.H.; Hwang, N.M.; Hyeon, T. Ultra-Large-Scale Syntheses of Monodisperse Nanocrystals. Nat. Mater. 2004, 3, 891-895. [CrossRef] [PubMed]

34. Yu, W.W.; Falkner, J.C.; Yavuz, C.T.; Colvin, V.L. Synthesis of Monodisperse Iron Oxide Nanocrystals by Thermal Decomposition of Iron Carboxylate Salts. Chem. Commun. 2004, 2306-2307. [CrossRef] [PubMed]

35. Hanson, E.L.; Schwartz, J.; Nickel, B.; Koch, N.; Danisman, M.F. Bonding Self-Assembled, Compact Organophosphonate Monolayers to the Native Oxide Surface of Silicon. J. Am. Chem. Soc. 2003, 125, 16074-16080. [CrossRef] [PubMed]

36. Panic, S.; Bajac, B.; Rakić, S.; Kukovecz; Kónya, Z.; Srdić, V.; Boskovic, G. Molybdenum Anchoring Effect in Fe-Mo/MgO Catalyst for Multiwalled Carbon Nanotube Synthesis. React. Kinet. Mech. Catal. 2017, 122, 775-791. [CrossRef] 
37. He, M.; Zhang, L.; Jiang, H.; Yang, H.; Fossard, F.; Cui, H.; Sun, Z.; Wagner, J.B.; Kauppinen, E.I.; Loiseau, A. FeTiO Based Catalyst for Large-Chiral-Angle Single-Walled Carbon Nanotube Growth. Carbon 2016, 107, 865-871. [CrossRef]

38. Harutyunyan, A.R.; Chen, G.; Paronyan, T.M.; Pigos, E.M.; Kuznetsov, O.A.; Hewaparakrama, K.; Kim, S.M.; Zakharov, D.; Stach, E.A.; Sumanasekera, G.U. Preferential Growth of Single-Walled Carbon Nanotubes with Metallic Conductivity. Science 2009, 326, 116-120. [CrossRef]

39. Dubey, M.; Weidner, T.; Gamble, L.J.; Castner, D.G. Structure and Order of Phosphonic Acid-Based Self-Assembled Monolayers on $\mathrm{Si}(100)$. Langmuir 2010, 26, 14747-14754. [CrossRef]

40. Mutin, P.H.; Lafond, V.; Popa, A.F.; Granier, M.; Markey, L.; Dereux, A. Selective Surface Modification of $\mathrm{SiO}_{2}-\mathrm{TiO}_{2} \mathrm{Supports}_{\text {with }}$ Phosphonic Acids. Chem. Mater. 2004, 16, 5670-5675. [CrossRef]

41. Thissen, P.; Valtiner, M.; Grundmeier, G. Stability of Phosphonic Acid Self-Assembled Monolayers on Amorphous and SingleCrystalline Aluminum Oxide Surfaces in Aqueous Solution. Langmuir 2010, 26, 156-164. [CrossRef]

42. Zhao, R.; Rupper, P.; Gaan, S. Recent Development in Phosphonic Acid-Based Organic Coatings on Aluminum. Coatings 2017, 7, 133. [CrossRef]

43. Smolensky, E.D.; Park, H.Y.E.; Berquó, T.S.; Pierre, V.C. Surface Functionalization of Magnetic Iron Oxide Nanoparticles for MRI Applications-Effect of Anchoring Group and Ligand Exchange Protocol. Contrast Media Mol. Imaging 2011, 6, 189-199. [CrossRef] [PubMed]

44. Cross, S.N.W.; Rochester, C.H. Infrared Study of the Adsorption of Ethyl Isocyanate on Silica Immersed in Carbon Tetrachloride. J. Chem. Soc. Faraday Trans. 1 Phys. Chem. Condens. Phases 1981, 77, 1945-1952. [CrossRef]

45. Lewis, W.K.; Rosenberger, A.T.; Gord, J.R.; Crouse, C.A.; Harruff, B.A.; Fernando, K.A.S.; Smith, M.J.; Phelps, D.K.; Spowart, J.E.; Guliants, E.A.; et al. Multispectroscopic (FTIR, XPS, and TOFMS-TPD) Investigation of the Core-Shell Bonding in Sonochemically Prepared Aluminum Nanoparticles Capped with Oleic Acid. J. Phys. Chem. C 2010, 114, 6377-6380. [CrossRef]

46. Van den Brand, J.; Snijders, P.C.; Sloof, W.G.; Terryn, H.; De Wit, J.H.W. Acid-Base Characterization of Aluminum Oxide Surfaces with XPS. J. Phys. Chem. B 2004, 108, 6017-6024. [CrossRef]

47. Alexander, M.R.; Thompson, G.E.; Beamson, G. Characterization of the Oxide/Hydroxide Surface of Aluminum Using X-Ray Photoelectron Spectroscopy: A Procedure for Curve Fitting the O 1s Core Level. Surf. Interface Anal. 2000, 29, 468-477. [CrossRef]

48. Zähr, J.; Oswald, S.; Türpe, M.; Ullrich, H.J.; Füssel, U. Characterisation of Oxide and Hydroxide Layers on Technical Aluminum Materials Using XPS. Vacuum 2012, 86, 1216-1219. [CrossRef]

49. Do, B.P.H.; Nguyen, B.D.; Nguyen, H.D.; Nguyen, P.T. Synthesis of Magnetic Composite Nanoparticles Enveloped in Copolymers Specified for Scale Inhibition Application. Adv. Nat. Sci. Nanosci. Nanotechnol. 2013, 4, 045016. [CrossRef]

50. Gupta, R.; Pancholi, K.; Sa, R.D.E.; Murray, D.; Huo, D.; Droubi, G.; White, M.; Njuguna, J. Effect of Oleic Acid Coating of Iron Oxide Nanoparticles on Properties of Magnetic Polyamide-6 Nanocomposite. JOM 2019, 71, 3119-3128. [CrossRef]

51. Okhrimenko, D.V.; Nielsen, C.F.; Lakshtanov, L.Z.; Dalby, K.N.; Johansson, D.B.; Solvang, M.; Deubener, J.; Stipp, S.L.S. Surface Reactivity and Dissolution Properties of Alumina-Silica Glasses and Fibers. ACS Appl. Mater. Interfaces 2020, 12, 36740-36754 [CrossRef] [PubMed]

52. Hoque, E.; DeRose, J.A.; Bhushan, B.; Mathieu, H.J. Self-Assembled Monolayers on Aluminum and Copper Oxide Surfaces: Surface and Interface Characteristics, Nanotribological Properties, and Chemical Stability. Appl. Scanning Probe Methods IX 2007, 111, 235-281. [CrossRef]

53. Queffélec, C.; Petit, M.; Janvier, P.; Knight, D.A.; Bujoli, B. Surface Modification Using Phosphonic Acids and Esters. Chem. Rev. 2012, 112, 3777-3807. [CrossRef] [PubMed]

54. Gouzman, I.; Dubey, M.; Carolus, M.D.; Schwartz, J.; Bernasek, S.L. Monolayer vs. Multilayer Self-Assembled Alkylphosphonate Films: X-Ray Photoelectron Spectroscopy Studies. Surf. Sci. 2006, 600, 773-781. [CrossRef]

55. Hoque, E.; Derose, J.A.; Kulik, G.; Hoffmann, P.; Mathieu, H.J.; Bhushan, B. Alkylphosphonate Modified Aluminum Oxide Surfaces. J. Phys. Chem. B 2006, 110, 10855-10861. [CrossRef] [PubMed]

56. Bayer, B.C.; Fouquet, M.; Blume, R.; Wirth, C.T.; Weatherup, R.S.; Ogata, K.; Knop-Gericke, A.; Schlögl, R.; Hofmann, S.; Robertson, J. Co-Catalytic Solid-State Reduction Applied to Carbon Nanotube Growth. J. Phys. Chem. C 2012, 116, 1107-1113. [CrossRef] 